\title{
Mechanical behavior of tubular welded T-joints with circular and elliptical cross-sections
}

\author{
Salah Eddine JALAL ${ }^{1}$, Ahmed MJIDILA ${ }^{2}$, Zakaria El MASKAOUI ${ }^{3}$, Lahbib \\ BOUSSHINE $^{4}$ \\ ${ }^{1,2,3,4}$ (Laboratory of construction technology and industrial systems, High National School of Electricity and \\ Mechanics/ Hassan II University, Casablanca, Morocco)
}

\begin{abstract}
The aim of this work is to analyze, numerically, the elastic and elastoplastic behavior of three tubular T-joints with different cross-sections of braces. The first one is circular and the others are elliptical but assembled differently (longitudinal and transversal positions). The elastic study is to compare, in three charge cases, the geometric stress variation around the weld toe for the three T-joints. In the elastoplastic study, the limit loads of these joints were compared for each load case. In the order to facilitate interpretations, the results are presented in graphical form. The numerical simulations are performed using Patran and Nastran softweres.

Keywords : Circular cross-section, Elasticity, Elastoplasticity, Elliptical cross-section, Hot spot, Limit load.
\end{abstract}

\section{INTRODUCTION}

The tubular welded joints find applications in many fields of mechanical engineering. We quote: water pipes, tripods, gateways and offshore platform supports. These supports are mainly formed by a set of structural element welded together to form tubular joints with different geometrical configurations (T, Y, K, KT, DT, DY, $\mathrm{DK}, \mathrm{DKT}, \ldots$... In the most cases, the structural elements are tubes with circular cross-sections. Hence the idea to compare elastic and elastoplastic responses of these kinds of joints with others which the braces have elliptical cross-sections.

Several studies have been addressed to analyze the tubular welded joint behaviors. In [1], Ghanameh et al. have carried out the simulations to evaluate the local stress variation in the vicinity of toe weld linking chords and braces. This is carried for several kinds of planar joints with circular cross-sections under combined loading. In [2], Lee studied firstly, the T and Y-joints under tensile loading, in plane and out plane bending. Secondly, the K and DT-joint under balanced loading. Soh et al. [3] have also studied the DT, K and KT-joints in three cases of balanced loads, TEN, IPB and OPB. In [4], a comparative study of elastic and elastoplastic behaviors for T, Y, DT and DY-joints was performed. This study found that the joints with inclined braces are more robust than those having perpendicular braces. This is valid for elastic and elastoplastic studies. In [5], an analysis of the influence of the geometrical parameters of the stress concentration factor was performed. This study was undertaken for tubular KT-joints with circular cross-sections but with internal stiffeners. In this work, it was noted that the authors have introduced a new adimensional parameter which is directly proportional to the size of the stiffeners. The study of numerical simulation, which the mesh has been validated experimentally, has shown that the SCF decreases when the new parameter increases.

\section{CHOICE OF JOINTS AND BOUNDARY CONDITIONS}

Three specimens named $T_{1}, T_{2}$ and $T_{3}$ will be studied in this work. They have identical chords with circular cross-sections. The brace of $\mathrm{T}_{1}$ has a circular cross-section, $\mathrm{T}_{2}$ and $\mathrm{T}_{3}$ have braces with elliptical crosssections of the same dimensions but they are arranged differently (Fig. 8).

For each specimen, three load cases will be treated, tensile loading (TEN), in plane bending (IPB) and out plane bending (OPB). The loads will be applied at the free ends of braces. The ends of the chords are, all the time, fixed. 


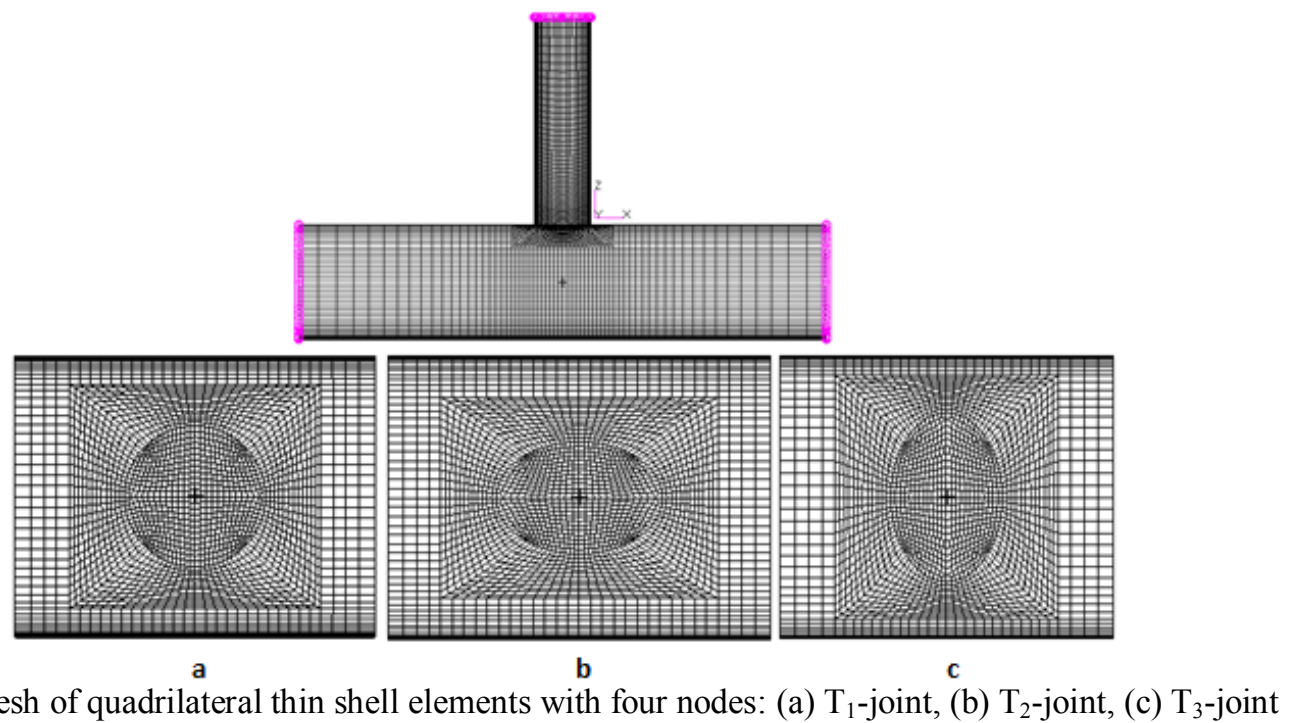

Fig. 1 - Mesh of quadrilateral thin shell elements with four nodes: (a) $T_{1}$-joint, (b) $T_{2}$-joint, (c) $T_{3}$-joint

The mesh is made using Patran software, while post-processing is handled using Nastran software. For the three specimens, the vicinity of the weld is subdivided into 96 finite elements in the aim to collect the maximum stresses values along the weld toe (Fig. 1).

The material chosen for this study is the construction steel of Young's modulus $2.1 \times 10^{5} \mathrm{MPa}$, yeld point 240MPa and Poisson's ratio 0.33. For the elastoplastic study which we determine the limit loads, the material will be considered elastic perfectly plastic.

\section{ELASTIC BEHAVIOR OF JOINTS}

The three specimens $T_{1}, T_{2}$ and $T_{3}$ are submitted independently to three kinds of external loads, TEN, IPB and OPB. For each load case, will be presented in same graph the local stress evolution $\sigma_{\mathrm{L}}$ in term of the angle $\psi$. This is for the three joints.

\section{Tensile loading}

In the case of tensile loading, a force equal to $10^{4} \mathrm{~N}$ is applied to the brace's free end. For the three kinds of joints studied, we note that the hot spot is located at the Saddle with 194MPa, $185 \mathrm{MPa}$ and $208 \mathrm{MPa}$ for $\mathrm{T} 1, \mathrm{~T} 2$ and $\mathrm{T} 3$ respectively. We note that in the vicinity of the saddle, the $\mathrm{T}_{3}$-joint has the highest local stress value (Fig. 2). But apart from this location, the local stress of $T_{2}$ is predominates. We also note that the smallest value of the local stress is recorded in the Crown; this is for the three specimens.

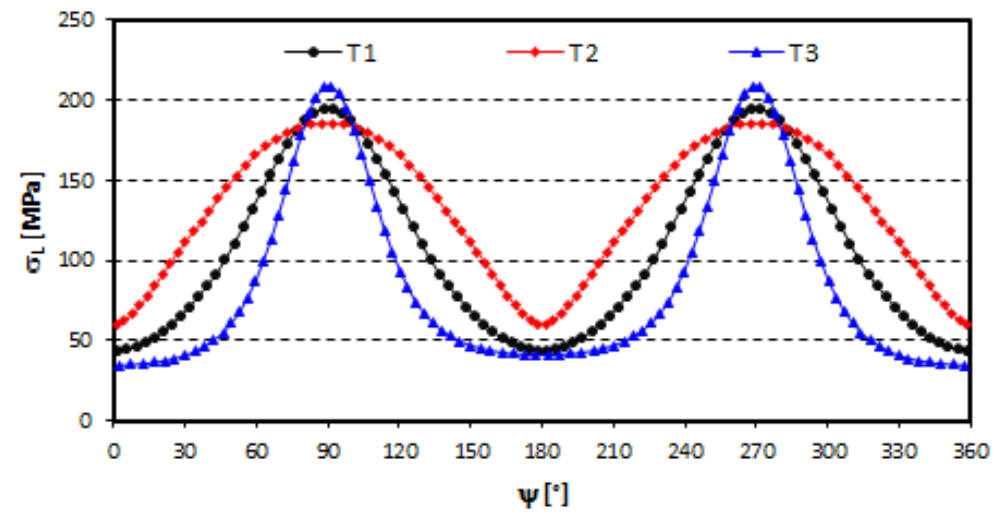

Fig. 2 - Evolution of the local stress around the weld toe following a tensile force of $10 \mathrm{kN}$ applied at the brace's free end

\section{Loading of in plan bending}

In this load case, in plane bending is applied at the free end of the brace. As in the case of tensile, the curve of the $T_{1}$-joint is always between these of $T_{2}$ and $T_{3}$-joints. But in the vicinity of Crown, the curves for $T_{1}$ and $\mathrm{T}_{3}$-joints are almost confounded, i.e. we also note that the Crown and its neighborhood are a hot area for all specimens with a predominance of $\mathrm{T}_{2}$ which admits a maximum stress equal to $216 \mathrm{MPa}$ (Fig. 3). Conversely, 
compared to tensile case, the stress of $\mathrm{T}_{2}$-joint is dominant in the hot area. Far from this location, the geometrical stress of the $\mathrm{T}_{3}$-joint is the biggest.

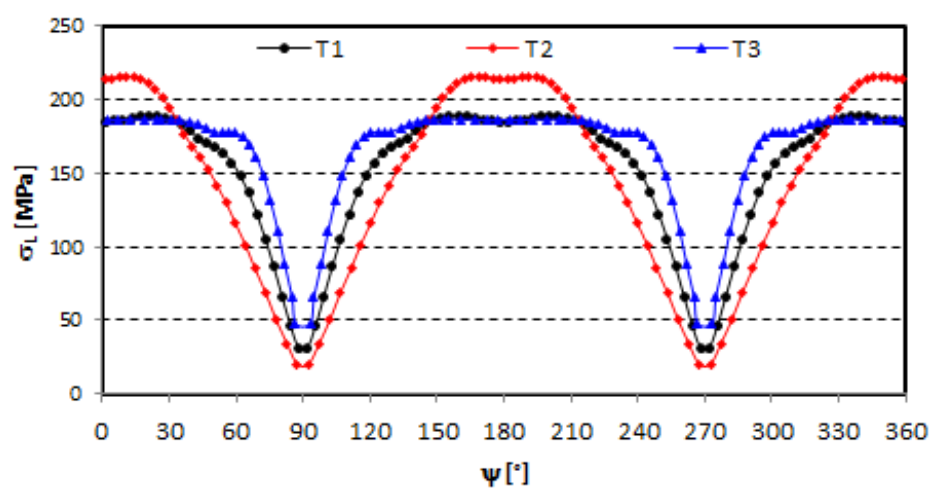

Fig. 3 - Evolution of the local stress around the weld toe following IPB of $2.5 \mathrm{kN}$ applied at the brace's free ends

\section{Loading of out plan bending}

The three joints are solicited with an external force equal to $1 \mathrm{kN}$ applied to the brace's free end perpendicularly to the symmetry plane of the specimens. We note that the hot spots are located at the saddle, for three specimens, like the tensile case. We also note that the local stress of the $T_{1}$-joint is between those for $T_{2}$ and $\mathrm{T}_{3}$-joints with a predominance of $\mathrm{T}_{2}$ throughout the weld. $\mathrm{T}_{1}$ and $\mathrm{T}_{3}$-joints have almost the same value of the local stress at the hot spot (Saddle in this case) which is equal to 212MPa. At the Crown, all specimens have approximately the same value of the geometrical stress (local) which is about 13MPa (Fig. 4).

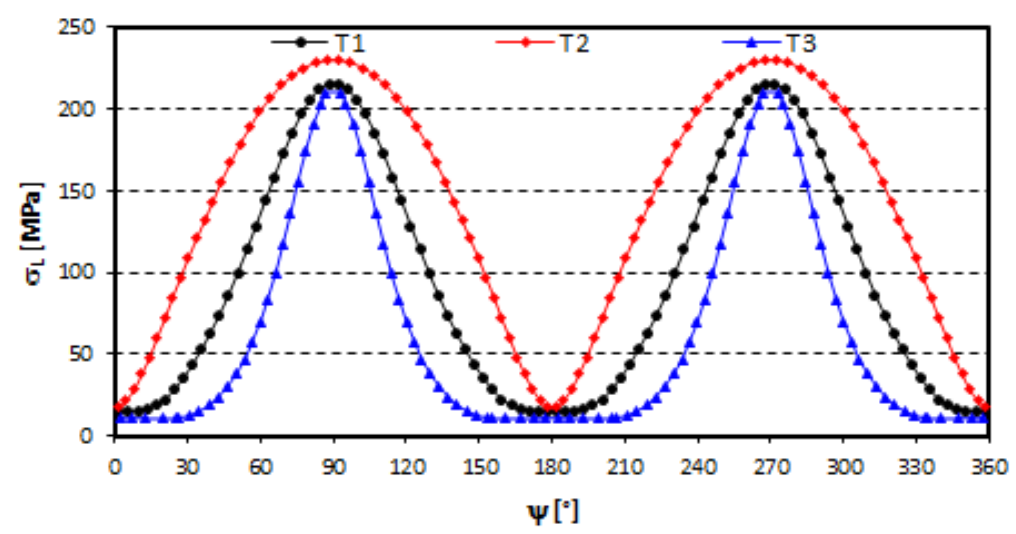

Fig. 4 - Evolution of the local stress around the weld toe following OPB of $1 \mathrm{kN}$ applied at the brace's free ends

\section{ELASTOPLASTIC BEHAVIOR OF JOINTS}

The aim of this work is to levy the force applied to the brace's free end in term of displacement. This will be performed in three load cases, TEN, IPB and OPB for each specimen. To facilitate comparison, the results will be exposed graphically. The first observation we can make is that all curves tend to a limit load whatever the load and for all joints.

\section{Tensile loading}

In this case load, we note that the curve for $\mathrm{T}_{1}$-joint is located between the other two curves with a predominance of $\mathrm{T}_{3}$-joint. We also note that the limit load of the $\mathrm{T}_{1}$-joint is equal to $87 \mathrm{kN}$ while those $\mathrm{T}_{2}$-joint and $\mathrm{T}_{3}$-joint are equal to $74 \mathrm{kN}$ and $93 \mathrm{kN}$ respectively (Fig. 5). 


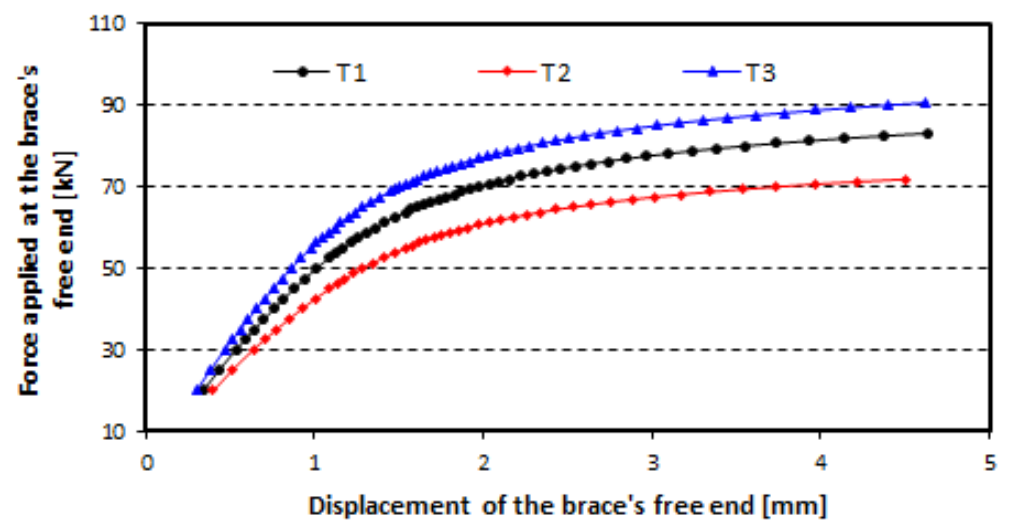

Fig. 5 - Variation of the tensile force in term of the displacement of the brace's free end

\section{Loading of in plane bending}

In this load case, we note that $T_{1}$ and $T_{2}$-joints have the same elastoplastic responses, i.e. they have the same load limit which is equal to $11 \mathrm{kN}$. This value is higher than recorded for $T_{3}$-joint which is equal to $9.8 \mathrm{kN}$ (Fig. 6).

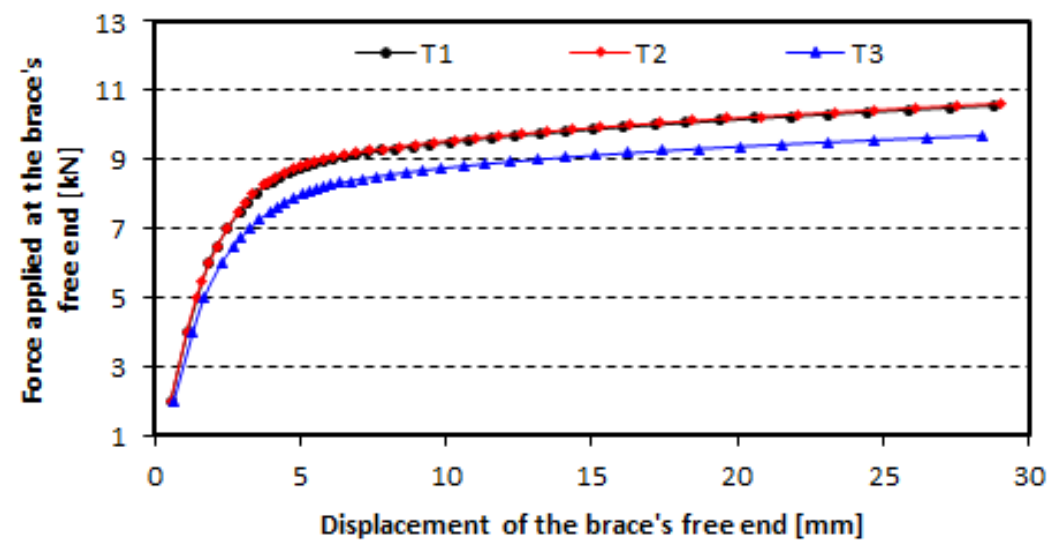

Fig. 6 - Variation of the IPB loading in term of the displacement of the brace's free end

\section{Loading out plane bending}

The elastoplastic response in this case load is similar to the tensile case, i.e. the curve of $\mathrm{T}_{1}$-joint is between $T_{2}$ and $T_{3}$-joint with predominance of $T_{3}$. The limit loads of $T_{1}, T_{2}$ and $T_{3}$-joints are equal to $5 \mathrm{kN}$, $6.8 \mathrm{kN}$ and $8.8 \mathrm{kN}$ respectively (Fig. 7).

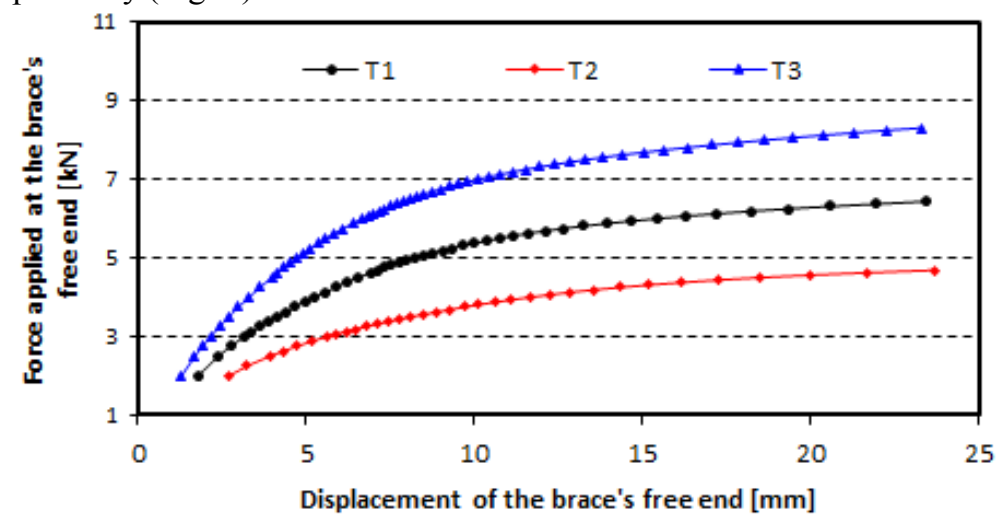

Fig. 7 - Variation of the OPB loading in term of the displacement of the brace's free end

\section{CONCLUSIONS}

The elastic study of three joints $T_{1}, T_{2}$ and $T_{3}$ led to the following conclusions:

- In the TEN and OPB load cases, whatever the shape of the brace cross-section, the hot spot is located at the Saddle.

- In the IPB load case, the hot areas coincide with Crown and its vicinity whatever the shape of the brace crosssection. 
- The joints with circular braces and with longitudinal elliptical braces have the same SCF under IPB loading. - Around the toe weld, the geometric stress of the joints with circular brace is, all the time, between those with the elliptical braces. This is for all loading cases.

The elastoplastic study for $\mathrm{T}_{1}, \mathrm{~T}_{2}$ and $\mathrm{T}_{3}$-joints led to the following conclusions:

- In the TEN and OPB load cases, the limit load of the joint with circular brace is, all the time, between those with the elliptical braces.

- The joints with circular and longitudinal elliptical braces have the same limit load under IPB loading.

- For all joints and all load cases, the limit load in the IPB load case is more important to compare with IPB load case.

\section{REFERENCES}

[1] M. F. Ghanameh, D. Thevenet and A. Zeghloul, Evaluation of stress concentration for planar tubular joints, Transactions of Nonferrous Metals Society of China, 16(1), 2006, 1-10.

[2] M. M. K. Lee, Estimation of stress concentrations in single-sided welds in offshore tubular joints, International Journal of Fatigue, 21(9), 1999, 895-908.

[3] A. K. Soh, C. K. Soh, 'Hot spot' stresses of K tubular joints subjected to combined loading, Journal of Constructional Steel Research, 26(2-3), 1993, 125-140.

[4] S. Jalal, L. Bousshine, Elastoplastic behavior of T, Y, DT and DY-tubular joints under axial loading, IOSR Journal of Mechanical and Civil Engineering, 4(3), 2012, 19-25.

[5] H. Ahmadi, M. A. Lotfollahi-Yaghin, S. Yong-Bo, M. H. Aminfar, Parametric study and formulation of outer-brace geometric stress concentration factors in internally ring-stiffened tubular KT-joints of offshore structures, Applied Ocean Research, 38, 2012, 74-91.

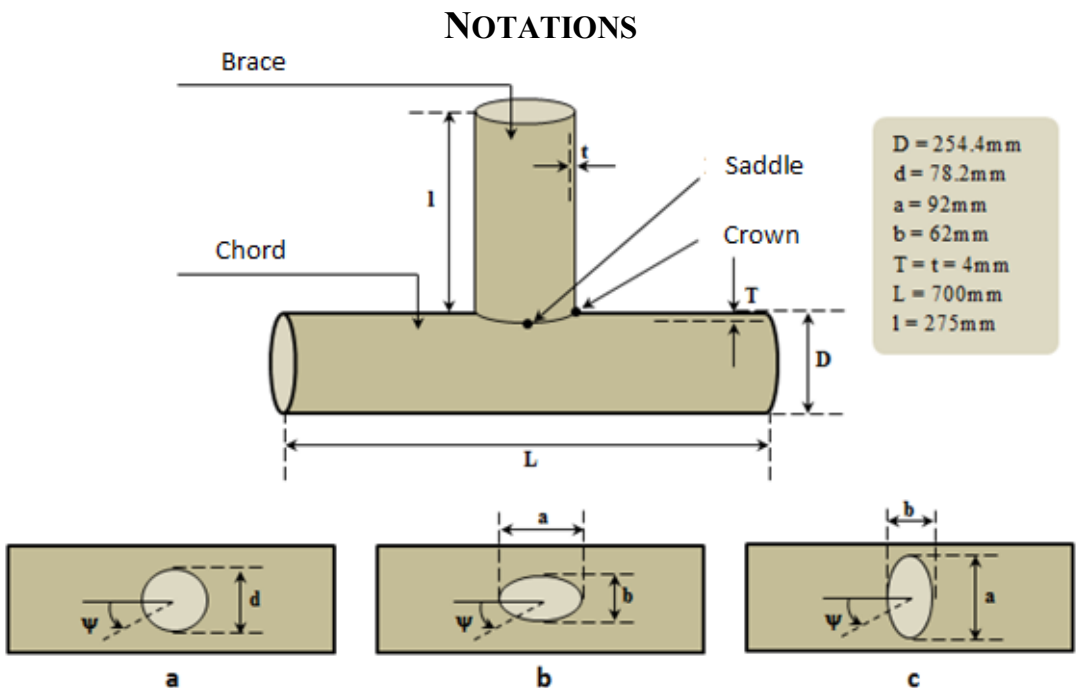

Fig. 8 - T-joints : (a) T-jont with circular brace $\mathrm{T}_{1}$, (b) $\mathrm{T}$-joint with longitudinal elliptical brace $\mathrm{T}_{2}$,

(c) T-joint with Transversal elliptical brace $\mathrm{T}_{3}$.

$\begin{array}{ll}\text { TEN } & \text { : Tensile load } \\ \text { IPB } & \text { : In Plane Bending } \\ \text { OPB } & \text { : Out Plane Bending } \\ \mathrm{D} & \text { : Outside diameter of chord } \\ \mathrm{d} & \text { : Outside diameter of brace } \\ \mathrm{T} & : \text { Chord's thickness } \\ \mathrm{t} & \text { : Brace's thickness } \\ \mathrm{L} & \text { : Chord's length } \\ \mathrm{l} & \text { : Brace's length } \\ \psi & : \text { Angle orienting the weld measured from Crown } \\ \sigma_{\mathrm{L}} & : \text { Local Stress } \\ \mathrm{SFC} & : \text { Stress Factor Concentration }\end{array}$

